\title{
Existence, uniqueness and convergence of approximate solutions of nonlocal functional differential equations
}

\section{MusLim and R. P. AgARWAL}

\section{ABSTRACT.}

In this paper, we study a class of nonlocal abstract functional differential equations in a separable Hilbert space $H$. Using the theory of analytic semigroups we establish the existence, uniqueness and convergence of approximate solutions. We also give some examples to illustrate the applications of the abstract results.

Department of Mathematics

Birla Institute of TeChNOlogy AND SCIENCE Pilani-Goa CAMPUS

GOA, INDIA

E-mail address: malikiisc@gmail.com

DePartMent of Mathematical SCiences

FLORIDA INSTITUTE OF TECHNOLOGY

150 WEST UNIVERSITY BOULEVARD

MELBOURNE, FL 32901, USA

E-mail address: agarwalefit.edu 